\title{
Heat exposure during non-motorized travel: Implications for transportation policy under
}

climate change

Alex Karner ${ }^{\mathrm{a}, 1}$, David M. Hondula ${ }^{\mathrm{b}}$, Jennifer K. Vanos ${ }^{\mathrm{c}}$ ${ }^{\mathrm{c}}$ Atmospheric Science Research Group, Department of Geosciences, Texas Tech University, 14 Lubbock, TX 49409

Final manuscript submitted for publication in the Journal of Transport \& Health

${ }^{1}$ Corresponding author. Phone: +1-404-385-5123. Email: alex.karner@coa.gatech.edu 


$\begin{aligned} 1 & \text { ABSTRACT } \\ 2 & \text { Transportation planning agencies around the world are increasingly seeking to develop } \\ 3 & \text { transportation systems that encourage walking, bicycling, and transit use in order to } \\ 4 & \text { simultaneously achieve public health and environmental sustainability goals. Under future } \\ 5 & \text { scenarios that will see increasing global mean temperatures, trips that entail physical exertion } \\ 6 & \text { outdoors are likely to account for substantial portions of some individuals' overall exposure to } \\ 7 & \text { potentially dangerously high air temperatures. This exposure pathway is poorly understood. In } \\ 8 & \text { this study we develop a new method to assess outdoor heat exposure during non-motorized } \\ 9 & \text { transportation activities by combining simulated urban meteorology and transportation-activity } \\ 10 & \text { data. We demonstrate its utility through its application to several real-world planning issues } \\ 11 & \text { using data from the San Francisco Bay Area. Specifically, we examine spatial and social } \\ 12 & \text { disparities in heat exposure and find that socially disadvantaged (low-income people and zero- } \\ 13 & \text { vehicle households) groups are disproportionately exposed to transport-related heat. Since the } \\ 14 & \text { propensity to walk and bicycle tends to decrease with socioeconomic status (SES) and because } \\ 15 & \text { lower SES groups are more vulnerable to heat-related health impacts, efforts to mitigate heat } \\ 16 & \text { exposure can be of disproportionate benefit to these disadvantaged groups. Finally, we } \\ 17 & \text { demonstrate how the results can be used to supplement more traditional indicators of heat } \\ 18 & \text { vulnerability that to date do not directly account for actual length of outdoor exposure. The } \\ 19 & \text { methodology developed here has the potential to guide healthy, sustainable, and equitable urban } \\ 20 & \text { planning efforts. }\end{aligned}$




\section{INTRODUCTION}

Increasing the number of travelers walking, bicycling, and using public transportation to meet daily needs is a favored contemporary transportation policy goal, as it can simultaneously lead to reductions in greenhouse gas emissions, reduced congestion, and improvements in air quality and public health (Sallis et al. 2004; Hosking et al. 2011; Maizlish et al. 2012). At the same time, there is concern that adverse health outcomes associated with extreme heat will affect a larger portion of the population and/or become more severe in the future with continued planetary warming and urbanization (e.g., Patz et al. 2005; Hondula et al. 2014; Stone et al. 2014). Time outdoors represents an average of about $8 \%$ of total time use (Klepeis et al. 2001). Outdoor exposures are potentially some of the most important with respect to risks associated with extreme heat because they may occur simultaneously with physical exertion. As cities continue to grow and the climate continues to warm, it becomes increasingly important to understand the potential human health impacts of future transportation planning scenarios and their interplay with future climate.

Despite the inherent connection between non-motorized travel behavior and exposure to weather extremes, there is no prior research that quantifies its extent or examines the implications of extreme heat exposure for future transportation policy and planning. The amount of time individuals spend walking and bicycling is a function of individual attitudes and preferences, but also of land-use mixing and available transportation infrastructure (Hanson and Schwab 1987; Saelens et al. 2003). Lower-income residents and people of color are disproportionately likely to walk and/or bicycle, as well as to suffer from ill health (Pucher and Renne 2003; Plaut 2005; Marmot et al. 2008), however these same individuals travel less overall (Giuliano 2003). Further, the quality of urban outdoor environments is a major determinant of the health and well-being of city dwellers (Revi et al. 2014). Most of our current understanding of urban heat-health risks, however, is based on city-scale retrospective analyses of meteorological and health data (e.g., McMichael et al. 2008; Hondula et al. 2012). While research continues to refine the scale at which these analyses are conducted (Uejio et al. 2011; Hondula and Barnett 2014; Kovach et al. 2015), there is still very little understanding of the actual time and activity patterns associated with heat exposure. Even among studies explicitly aimed at identifying the most appropriate temperature metric for modeling heat-health risk, the focus remains almost entirely on fixedpoint measurements made outdoors (e.g., Barnett et al. 2010; Hajat et al. 2010; Zhang et al. 2012), with the indoor environment recently garnering increased attention in the context of heathealth risks (e.g, Quinn et al. 2014; Uejio et al. In press). New perspectives and approaches are needed that more rigorously consider all components of personal heat exposure to determine how risks will evolve, and identify opportunities for limiting adverse outcomes (Ebi and Semenza 2008).

This article seeks to contribute such perspectives by integrating two simulated data sources that have not previously been investigated together: travel-activity and urban meteorological models. Specifically, we develop a method for quantifying non-motorized transportation-driven exposure to dangerously high outdoor air temperatures using simulations of daily travel patterns and urban meteorological data from the San Francisco Bay Area, California. The method results in the creation of indicators that quantify "Individually Experienced Temperatures" (following Kuras et al. (2015)) estimated for trips made by foot or bicycle. In addition to documenting and validating the method, we show how the resultant indicators can be used to assess spatial and social disparities in exposure and supplement approaches to population vulnerability assessment that have historically focused on demographic measures. 
1 California is a particularly appropriate test site since the state has recently promulgated law and

2 policy regarding future regional growth patterns and transportation planning outcomes. The 3 overall aim of these recent laws and policies is to reduce driving while increasing the use of 4 public transportation and non-motorized modes by linking transportation and land-use policy 5 (Barbour and Deakin 2012). To comply with the law, transportation planning agencies in the 6 state maintain simulation models of future travel patterns, estimated using travel or activity surveys. We employ data from one such model describing fully disaggregate (i.e. individual- and household-level) travel patterns for a simulated travel day in the base year 2010. These results are combined with fine-scale (1 km resolution) urban meteorological reanalysis data representing a particularly hot day in August, 2010 that peaked at $99^{\circ} \mathrm{F}\left(37^{\circ} \mathrm{C}\right)$. This "extreme" heat situation is predicted to become relatively commonplace in California based on climate change scenarios (Miller et al. 2008). Our results provide new perspectives on exposure to extreme heat and can be used to guide public health and urban planning responses to climate change.

\section{MATERIALS AND METHODS}

Travel patterns and air temperature combine to influence an individual's exposure to heat. To understand the heat exposure of travelers using non-motorized modes, we required information on both travel-activity patterns (spatially and temporally resolved locations of urban residents) and the urban meteorology (spatially and temporally resolved air temperatures). We assembled these data from a variety of sources, as described below.

\subsection{Travel-activity data and demographics} To comply with US federal air quality regulations, regional transportation planning agencies maintain simulation models capable of predicting future travel patterns. There are two primary types of these "travel demand models": trip-based and activity-based (Algers et al. 2005). Tripbased models have been the workhorse travel demand modeling system for decades and are typically used to project future conditions on regional road and transit networks under different demographic, infrastructure, and land use scenarios (Ortúzar and Willumsen 2011). As summarized by McNally and Rindt (2007), the fundamental unit of analysis is the trip-a oneway journey from an origin to a destination. Trips are generated as a result of the demographics of a geographic area called a transportation analysis zone (TAZ), which is roughly equivalent in area to a census tract. In an activity-based model, tours are the fundamental unit, representing a closed series of trips beginning or ending at home or work that are undertaken to complete specific activities. This activity/tour approach is thought to better represent the manner in which individuals actually make travel decisions (Kitamura 1988; Algers et al. 2005; Davidson et al. 2007).

Both types of models output origin-destination matrices containing the number of trips moving from each origin to each destination TAZ within a region during specific time periods for each travel mode (automobile, public transit, walking, bicycling). Activity-based models additionally maintain the link between specific individuals and households and their tours, which makes it possible to summarize travel behavior by demographic group more accurately (Karner and Niemeier 2013).

For this study, we acquired data from the Metropolitan Transportation Commission (MTC), the federally designated metropolitan planning organization for the nine-county San Francisco Bay Area. MTC recently transitioned from a trip- to an activity-based model and developed a new regional transportation plan entitled Plan Bay Area (MTC and ABAG 2013). As part of that 
planning process, several land use and infrastructure scenarios were analyzed. We obtained all activity-based model data for the 2010 base year with outputs including lists of synthetic population members and households, their demographics, and a description of all trips and tours made during the simulated day. The simulations afford the opportunity to examine the travel behavior of the Bay Area's 7.1 million residents and 2.7 million households in 2010. On the simulated travel day (August 24, 2010), these residents made a total of 23.4 million trips, 3.6 million of which involved some non-motorized travel. In order to provide additional insight into the places where these trips took place, we summarized data from the American Community Survey 2008-2012 five-year estimates on household automobile ownership and poverty status (US Census Bureau 2014) at the TAZ-level.

\subsection{Urban meteorological data}

Air temperature data at a $1 \mathrm{~km}$ resolution were acquired from the Daymet dataset maintained by Oak Ridge National Laboratory (Thornton et al. 1997). Daymet provides daily minimum and maximum air temperatures for each $1 \mathrm{~km}$ grid, which were used in a sinusoidal function to interpolate hourly temperatures between the two extremes. For this study, we used a particularly hot summer day - August 24,2010 , when air temperature peaked at $99^{\circ} \mathrm{F}\left(37^{\circ} \mathrm{C}\right)$, more than 25 ${ }^{\circ} \mathrm{F}\left(14^{\circ} \mathrm{C}\right)$ above the climatological mean for late August. We selected this day because it was representative of an extreme event for the region: the day ranked fifth-hottest at San Francisco International Airport in the period 1980-2014. Hourly Daymet rasters were post-processed in R to generate a mean hourly temperature at the TAZ-level in order to link with daily travel patterns at the same scale. Because of the Bay Area's topography, air temperatures vary spatially throughout the day and are generally lower at locations in close proximity to the Pacific Ocean, and increase as one moves inland.

\subsection{Data synthesis: Heat exposure metrics}

Three transport modes - walk, bicycle, and walk-to-transit—comprised our definition of "nonmotorized transportation." Each trip involving non-motorized modes undertaken by the simulated Bay Area population was identified from the activity-based travel model, assuming fixed walking and biking speeds (of 3 and $12 \mathrm{mph}$, respectively, consistent with the travel model parameters) and access to suitable road and path networks. To assign approximate walking times to these simulated residents during transit trips, we used information concerning the walking distance required for transit access also derived from the model.

For each time interval in which an individual was traveling using non-motorized means, the air temperature from the corresponding $1 \mathrm{~km}$ grid and time interval were obtained from the Daymet data and added to that person's Individually Experienced Temperature (IET) "log" on an hourly basis. We operationalized IETs in two ways, recognizing that there is little consensus regarding what the most relevant heat exposures are for predicting health outcomes (Barnett et al. 2010; Hajat et al. 2010). These methods are summarized in equations 1 and 2, for total degree-minutes

38 (TDM) and extreme degree-minutes (EDM), respectively.

$$
\begin{gathered}
T D M_{i}=\sum_{j=1}^{N} m_{j} t_{h k} \\
E D M_{i}=\sum_{j=1}^{N} m_{j} t_{h k}, \text { where } t_{h k}>80^{\circ} \mathrm{F}\left(26.7^{\circ} \mathrm{C}\right)
\end{gathered}
$$


where $\mathrm{TDM}_{i}$ is total degree-minutes of exposure for person $i, m_{j}$ is minutes of travel for nonmotorized trip $j$, and $\mathrm{t}_{\mathrm{hk}}$ is the air temperature in the $1 \mathrm{~km}$ cell $k$ corresponding to the trip origin at hour $h$, and $N$ is the total number of non-motorized trips undertaken by individual $i . \mathrm{EDM}_{i}$ is extreme degree-minutes of exposure for person $i$, using the same definitions as for TDM but only considering temperature exposures greater than $80^{\circ} \mathrm{F}\left(26.7^{\circ} \mathrm{C}\right) .^{2}$

Both degree-minute metrics increase proportionately with time spent traveling and/or with temperature. The two metrics would display perfect correlation with exposure time if the air temperatures were the same across the region for the entire day. TDM and EDM will differ for different individuals with the same exposure time to the extent that temperatures vary spatially and temporally throughout the day and non-motorized travel behavior rates also vary. Air temperature is likely to vary across the region in ways that both influence and affect the exposure of individuals engaged in non-motorized travel. The two heat exposure metrics are designed to reveal these differences.

\section{$14 \quad 2.4$ Data synthesis: Heat vulnerability metrics}

Prior work has documented that human vulnerability to environmental hazards, like extreme heat, is a function of physical exposure, sensitivity, and adaptive capacity (Turner et al. 2003; Polsky et al. 2007; Chow et al. 2012). Sensitivity refers to underlying demographic factors that place particular populations at risk, such as age and race. Adaptive capacity refers to the ability of a particular system to respond to change or to recover from an extreme incident, which may include variables that describe social ties or access to cooling spaces. Prior work has rarely considered actual physical exposure when estimating vulnerability, instead relying on demographic measures that place particular populations at risk from exposure and measurements of outdoor air or surface temperature (e.g., Uejio et al. 2011; Harlan et al. 2012). IETs can thus be used as a component of a larger vulnerability metric, wherein population demographics and place characteristics are combined to identify locations that contain both vulnerable people and high temperature exposures.

In order to provide an initial demonstration of the utility of such an approach, we propose a vulnerability measure that incorporates three different variables related to certain aspects of exposure, sensitivity, and adaptive capacity. Vulnerability indices for heat often contain several times more variables than we are including in this demonstration case (e.g., Reid et al. 2009; Harlan et al. 2012; Wolf and McGregor 2013). We recommend that the strategy for incorporating direct exposure measures into such social vulnerability analyses be refined in collaboration with local public health agencies or in combination with other relevant public health data because many of the variables included to date in such analyses may, in part, be aiming to indirectly estimate exposure.

We calculate an indicator of heat vulnerability at the TAZ level following equation 3 ,

$$
V_{i}=E_{i}+T_{i}+\operatorname{Inc} c_{i}
$$

37 where $\mathrm{V}_{i}$ is the vulnerability score for TAZ $i, \mathrm{E}_{i}$ is the rank of TAZ $i$ in terms of total TDM, 38 where greater ranks indicate greater exposure, $\mathrm{T}_{i}$ is the ranking of TAZ $i$ in terms of per non39 motorized trip TDMs of exposure, and $\mathrm{Inc}_{i}$ is the rank of the TAZ in terms of the weighted mean

\footnotetext{
${ }^{2}$ In San Francisco, emergency resources are mobilized for homeless populations when daytime temperature exceeds $80^{\circ} \mathrm{F}$ (San Francisco Department of Public Health 2013). Additionally, Bay Area cities appear to experience a large absolute increase in heat-related mortality once that specific threshold is exceeded relative to other US cities (Anderson and Bell 2009).
} 
household income of non-motorized travelers where higher ranks indicate lower incomes. The weights are non-motorized travel time and are taken directly from the synthetic population. TAZs with higher scores on the equation 3 index will have a combination of both vulnerable individuals and high per trip and total trip temperature exposures. Combining the total and per trip metrics into a single vulnerability score will allow specific mitigations to be targeted to places where they will have a broad impact (high total exposure) as well as address acute needs (high per trip exposure). Although the indicator proposed in equation 3 does not include variables drawing from all three components of vulnerability, it is one of the first in the literature to include physical exposure time. Further refinements can be undertaken and variables included in future iterations.

113 RESULTS AND DISCUSSION

12 The results focus on demonstrating the utility of the calculated IET metrics by identifying patterns of heat exposure and vulnerability across places and demographic groups in the Bay Area. First, we discuss factors associated with the propensity to use non-motorized modes and investigate how well they are reflected in the simulated data employed here by summarizing observed non-motorized travel behavior. The travel behavior results suggest the potential for disparities in heat exposure. Second, we describe the validation and application of the heat exposure metrics to investigate disparities by income and automobile ownership categories. Finally, we illustrate how combining heat exposure with other demographic indicators of vulnerability can provide insight into locations where mitigation strategies can be targeted for maximum benefit.

\subsection{Non-motorized travel patterns}

Walking, bicycling, and using public transportation are activities disproportionately engaged in by people of color and low-income people (Pucher and Renne 2003; Pucher et al. 2011). The activity-based model results demonstrate that as household income increases from the lowest to the highest quintile, the mean number of non-motorized trips per worker and their combined non-motorized mode share - the proportion of their trips that involved some walking or bicycling - tend to decrease (Table 1). Simulated Bay Area workers in the lowest income quintile make approximately $47 \%$ more non-motorized trips per worker as those in the highest quintile, and are shown here to be almost twice as likely to make a trip using a non-motorized mode overall. These populations are less likely to have regular access to an automobile and more likely to live in central urban areas that have desirable destinations (including jobs, shopping, and schools) within distances reasonably accessible using non-motorized modes (Taylor and Morris 2015). They are also more likely to be vulnerable to heat-related morbidity and mortality (Harlan et al. 2012). At the same time, total number of trips and average trip distance increase with income and other indicators of socioeconomic status (Pucher and Renne 2003). Employment status is one of the most important predictors of travel behavior.

Table 1. Key properties of non-motorized travel by household income quintile for the modeled base year, 2010.

\begin{tabular}{ccc}
\hline Income decile & Mean non-motorized trips per worker & Non-motorized mode share \\
\hline 1 (lowest) & 0.759 & 0.245 \\
2 & 0.662 & 0.179 \\
3 & 0.600 & 0.155 \\
4 & 0.534 & 0.137 \\
5 (highest) & 0.518 & 0.133 \\
\hline
\end{tabular}


1 In addition to demographics, land use characteristics and transportation infrastructure affect the 2 propensity to walk, bicycle, and use public transit (Ewing and Cervero 2010; Pucher et al. 2011). 3 Areas with denser and more diverse land uses, frequent and proximate public transit, accessible 4 destinations, and pedestrian- and cyclist-friendly design features tend to see increased non5 motorized travel. The activity-based model data clearly demonstrate these patterns. As shown in 6 Fig. 1, non-motorized trip rates (as a proportion of total trips originating in each TAZ) are in the 7 highest quintile in the traditional urban centers of San Francisco and Oakland. The same figure 8 also shows high rates of walking, cycling, and transit use throughout the region, including 9 suburban cities in the East and North Bay including Vallejo, San Rafael, and Fairfield. These 10 more suburban areas contain pockets of relatively high population density and well-connected 11 street networks as well as demographics conducive to non-motorized travel. The demographic 12 overlays shown in Fig. 1 clearly demonstrate that, on average, high rates of non-motorized 13 tripmaking occur in TAZs with higher proportions of zero vehicle households and households in 14 poverty. The proportion of zero vehicle households increases by about 7.5 times from the lowest 15 to the highest quintile of non-motorized tripmaking. The same figure for households in poverty 16 (defined here as household earnings less than $200 \%$ of the federal poverty line) almost doubles 17 over the same range. 


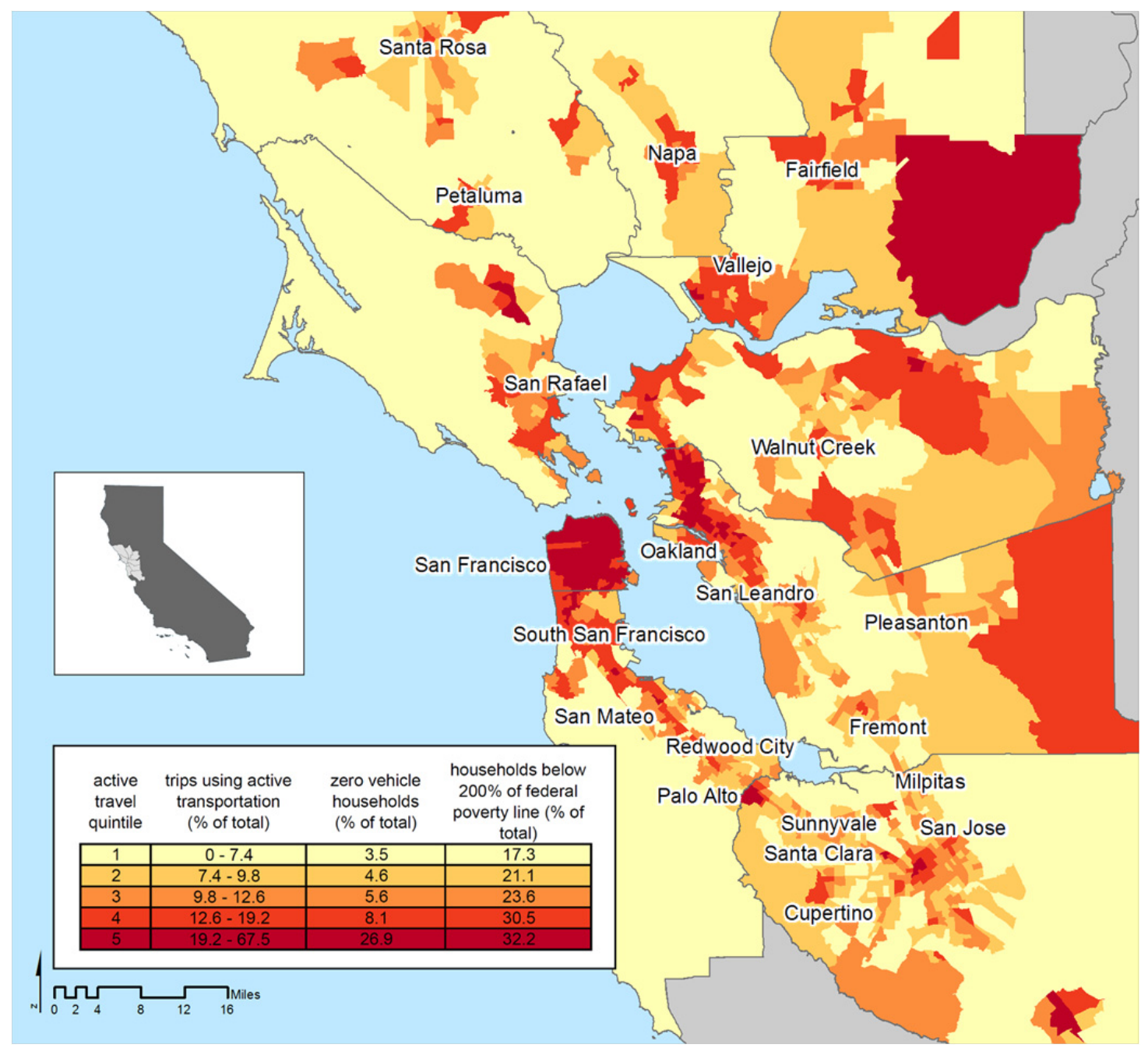

Fig. 1. Percentage of total trips originating in a transportation analysis zone (TAZ) made by active transportation grouped by quintile for the modeled base year scenario, 2010, and demographics from the American Community survey 2008-2012 five-year estimates. Darker shades indicate increasing proportions of trips made by nonmotorized modes. Labels included for primary cities of the San Jose-San Francisco-Oakland Combined Statistical Area as defined by the US Census Bureau. Location of the nine-county San Francisco Bay Area within California shown in inset.

\section{$8 \quad 3.2$ Heat exposure by demographic group and spatial variation}

\section{$9 \quad 3.2 .1$ Heat exposure metric evaluation}

10 IETs translate minutes of non-motorized travel into a metric that can be used to assess the 11 absolute magnitude of heat exposure (Kuras et al. 2015). Table 2 compares the quintile of nonmotorized travel time to the quintile of exposure (TDM) for those individuals that traveled by non-motorized modes to determine whether the IET metric (TDM) results in exposure classifications different than those that would result from travel time alone. Each cell contains thousands of people whose total heat exposure and travel behavior has been aggregated from the individual level. Analyzing all travelers or the total Bay Area population would result in a large number of zero values, skewing the quintiles; out of 23.4 million trips, 3.6 million were nonmotorized by our definition. Although the majority of individuals fall along the diagonal of the table, $34 \%$ of individuals change categories, either falling into a lower or higher exposure 
category than would be expected based on their non-motorized travel time. This result indicates that the spatial variation in temperature across the Bay Area and travel schedules across people is sufficient to warrant analysis separate from mere minutes of non-motorized travel. In other words, relying solely on travel time to represent heat exposure is likely to result in substantial misclassification. As urban form, weather, and travel patterns vary from city to city, this result may not hold in all locations - travel duration and time of travel may serve as an adequate proxy for temperature exposure in some cases, but not in all. More highly resolved temperature and health outcome data (e.g. at sub-1 km scales) will be required to determine the value added from an integrated temperature-time metric. Our recommendation from examining data from the Bay Area is that exposure must include a spatially resolved measure of temperature as well as time to properly inform public health interventions.

Table 2. Comparison of non-motorized travel time quintile and the exposure metric quintile (using TDM) by thousands of people.

\begin{tabular}{c|c|ccccc|}
\multicolumn{1}{c}{} & \multicolumn{5}{c}{ Non-motorized travel time quintile } \\
\cline { 3 - 7 } & & 1 & 2 & 3 & 4 & 5 \\
\hline 1 & 260 & 41 & 7.8 & 2 & 2 \\
$\begin{array}{c}\text { Exposure quintile } \\
\text { (total degree- } \\
\text { minutes) }\end{array}$ & 2 & 53 & 211 & 43 & 8 & 0 \\
3 & 0.4 & 126 & 135 & 52 & 2.6 \\
4 & 0 & 1.4 & 70 & 201 & 44 \\
5 & 0 & 0 & 0 & 52 & 265 \\
\hline
\end{tabular}

\subsubsection{Demographic variation: Income and automobile ownership}

15 Fig. 2 displays the degree-minute exposure metrics by household income for all travelers that made any trip (a) and all travelers that made any non-motorized trip (b). Note that confidence intervals calculated for these observations would generally be orders of magnitude smaller than the estimate because they are calculated based on a complete (but synthetic) population. The figure shows that both TDM and EDM are approximately $52 \%$ and $65 \%$ greater, respectively, for the lowest as compared to the highest income quintile. A one-way ANOVA revealed the quintile means significantly differed between groups for both $\operatorname{TDM}\left(\mathrm{F}_{4,7,053,229}=7,579, p<0.001\right)$ and $\operatorname{EDM}\left(\mathrm{F}_{4,7,053,229}=6,671, \mathrm{p}<0.001\right)$. When considering only those travelers that made any nonmotorized trip, the difference between income categories is substantially less pronounced. For TDM and EDM, the differences between the highest and lowest income quintiles were $9.2 \%$ and $18 \%$, respectively. These differences are still significant both for $\operatorname{TDM}\left(\mathrm{F}_{4,1,575,604}=1015, p<\right.$ $0.001)$ and $\operatorname{EDM}\left(\mathrm{F}_{4,1,575,604}=1266, p<0.001\right)$. This result is due at least in part to the enumeration of the entire Bay Area population in the activity-based model. 


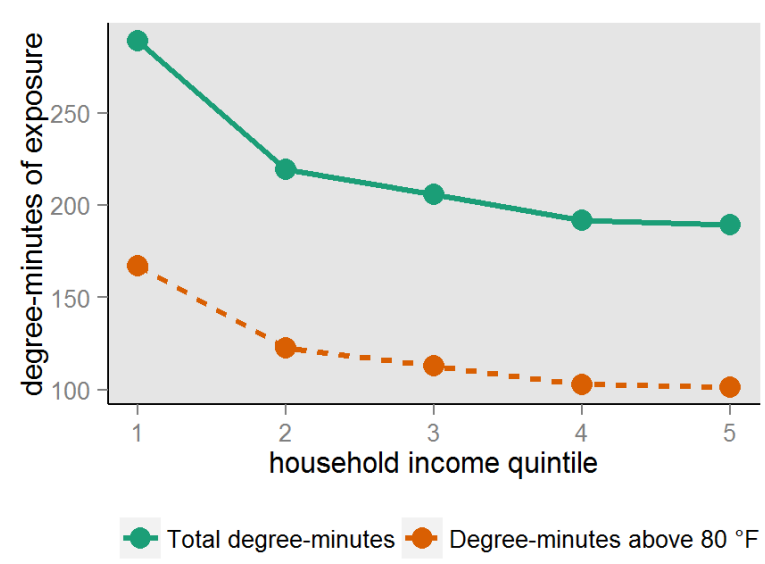

(a)

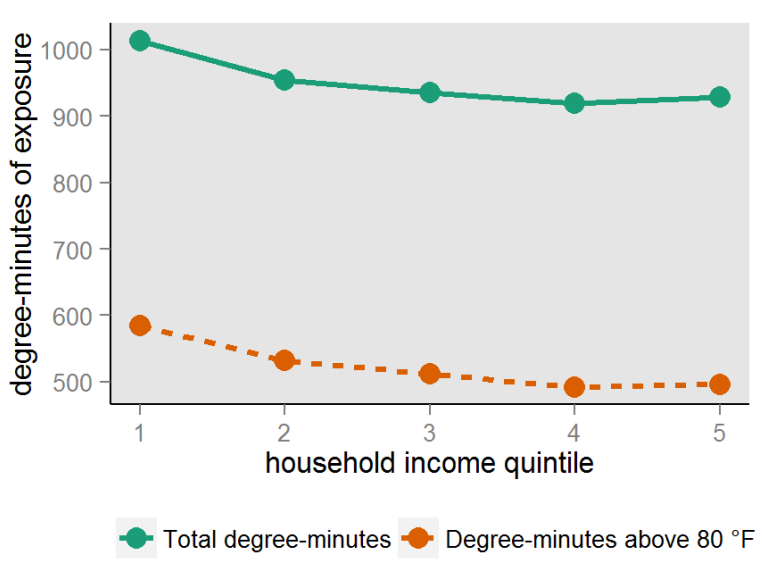

(b)

Fig. 2. Mean IETs based on TDM and EDM metrics by income quintile. Results shown for (a) All travelers and (b) All travelers using non-motorized modes on the simulated travel day.

Fig. 3 displays results for household automobile ownership categories, and shows greater disparities than for income categories. In general, traveling members of zero-vehicle households have between 4.6 (TDM) and 4.9 (EDM) times greater heat exposure than households with four or more automobiles. Again, these differences are significant across groups for TDM $\left(\mathrm{F}_{4,7,053,229}\right.$ $=166,463, p<0.001)$ and $\operatorname{EDM}\left(\mathrm{F}_{4,7,053,229}=102,681, p<0.001\right)$. These strong differences hold even when considering only those travelers that used non-motorized modes, although the magnitude of difference is reduced somewhat. Only considering non-motorized travelers, the difference between the highest and lowest automobile ownership categories are 37\% and 44\% for total and extreme degree-minutes, respectively. The ANOVA results indicate that these differences are also significant for $\operatorname{TDM}\left(\mathrm{F}_{4,1,575,604}=13,189, p<0.001\right)$ and $\operatorname{EDM}\left(\mathrm{F}_{4,1,575,604}=\right.$ $5,519, p<0.001)$.

14 Because zero-vehicle households are by definition more restricted in their travel choices than households with access to automobiles, their absolute air temperature exposures are similar for the most disadvantaged groups whether considering all traveling residents or only those residents that traveled by non-motorized modes.

Across the population, total exposure to high air temperatures during non-motorized travel is disproportionately borne by those that experience social disadvantage. In general, the results for EDM and TDM show similar patterns across the population, illustrating that extreme heat exposure and total heat exposure are correlated, at least using the definition of "extreme" adopted here (exposures exceeding $80^{\circ} \mathrm{F}$ or $26.7^{\circ} \mathrm{C}$ ), and considering the coarse spatial and temporal resolution of the air temperature data. Modifying the threshold used, and using the exposure metrics to predict health outcomes would provide insight into whether a different threshold would be more appropriate to capture spatial and demographic variation in heat-related illnesses.

27 When focusing only on those traveling by non-motorized modes, observed disparities are attenuated (Fig $3 \mathrm{~b}$ and $4 \mathrm{~b}$ ); all individuals using non-motorized modes, in the aggregate, experience similar average exposures across the Bay Area. For disadvantaged populations who are less likely to have access to cooling and are at elevated risk for heat-related illnesses and 
component of total daily exposure. The following section proposes a method to identify locations and populations that would benefit most from heat-related mitigations including the provision of 3 cooling and shade.

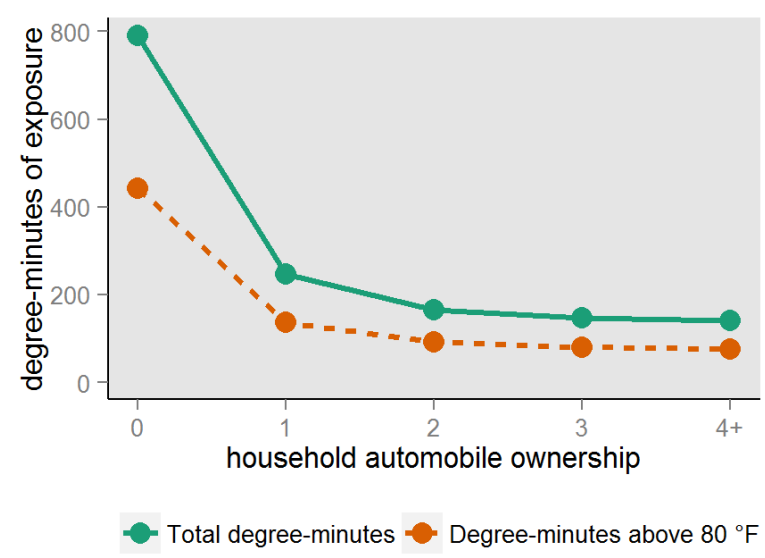

(a)

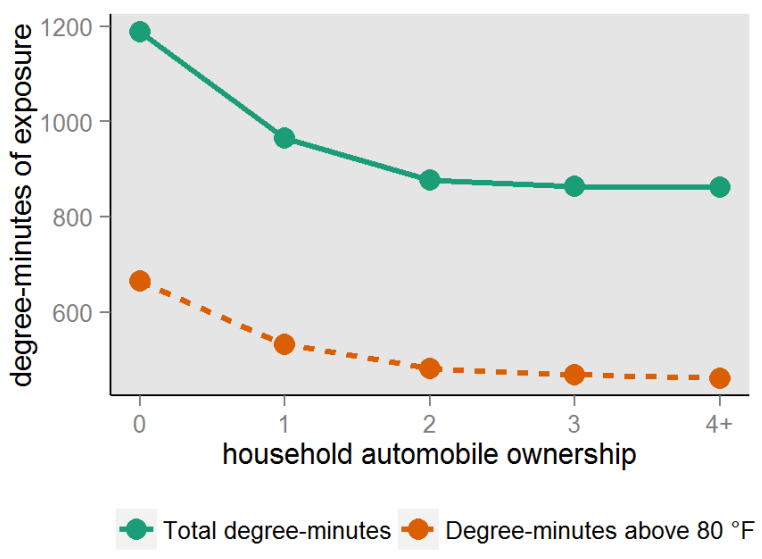

(b)

Fig. 3. Mean IETs by household automobile ownership. Results shown for (a) All travelers and (b) All travelers using non-motorized modes.

\subsubsection{Spatial variation and vulnerability}

These combined results present a challenge for those interested in mitigating heat exposures, including public health professionals and planners: where should mitigation efforts be targeted, given that rates of non-motorized travel simultaneously vary in space and across demographic groups? One option for effectively targeting mitigation is to create a composite indicator that takes into account a number of the different underlying demographic measures of concern. We calculated vulnerability scores for each TAZ using equation 3 . The distribution of the scores, along with a map of their geographic distribution is shown in Fig. 4. The results display some similarity with the earlier findings on non-motorized activity, with some high heat vulnerability scores in parts of the traditional urban areas, but in general the top quintile of vulnerability scores is much more widely dispersed with many high scoring areas located in the East and North Bay suburbs. When comparing Fig. 4 to Fig. 1, it is clear that despite widespread non-motorized activity in San Francisco, vulnerability may actually be quite low in general and limited to a cluster of TAZs located in the northeast quadrant of the city. In the East Bay, from San Leandro to Oakland and further north, vulnerability and non-motorized activity are more closely linked. These results illustrate how incorporating data on physical exposure with traditional demographic indicators of vulnerability can help to target mitigations for maximum effectiveness. Specifically for the Bay Area, this means considering locales outside of the traditional urban centers where non-motorized activity is concentrated. More suburban areas are also likely to contain combinations of demographics and land uses favorable to walking, bicycling, and public transit use. Additionally, walking and biking trips may be longer in these areas, as population and commercial activities will be less dense and destinations more dispersed. These land use characteristics, combined with the Bay Area's prevailing climate, are likely to result in greater per-trip IETs in these areas which increases vulnerability as calculated by equation 3 . 


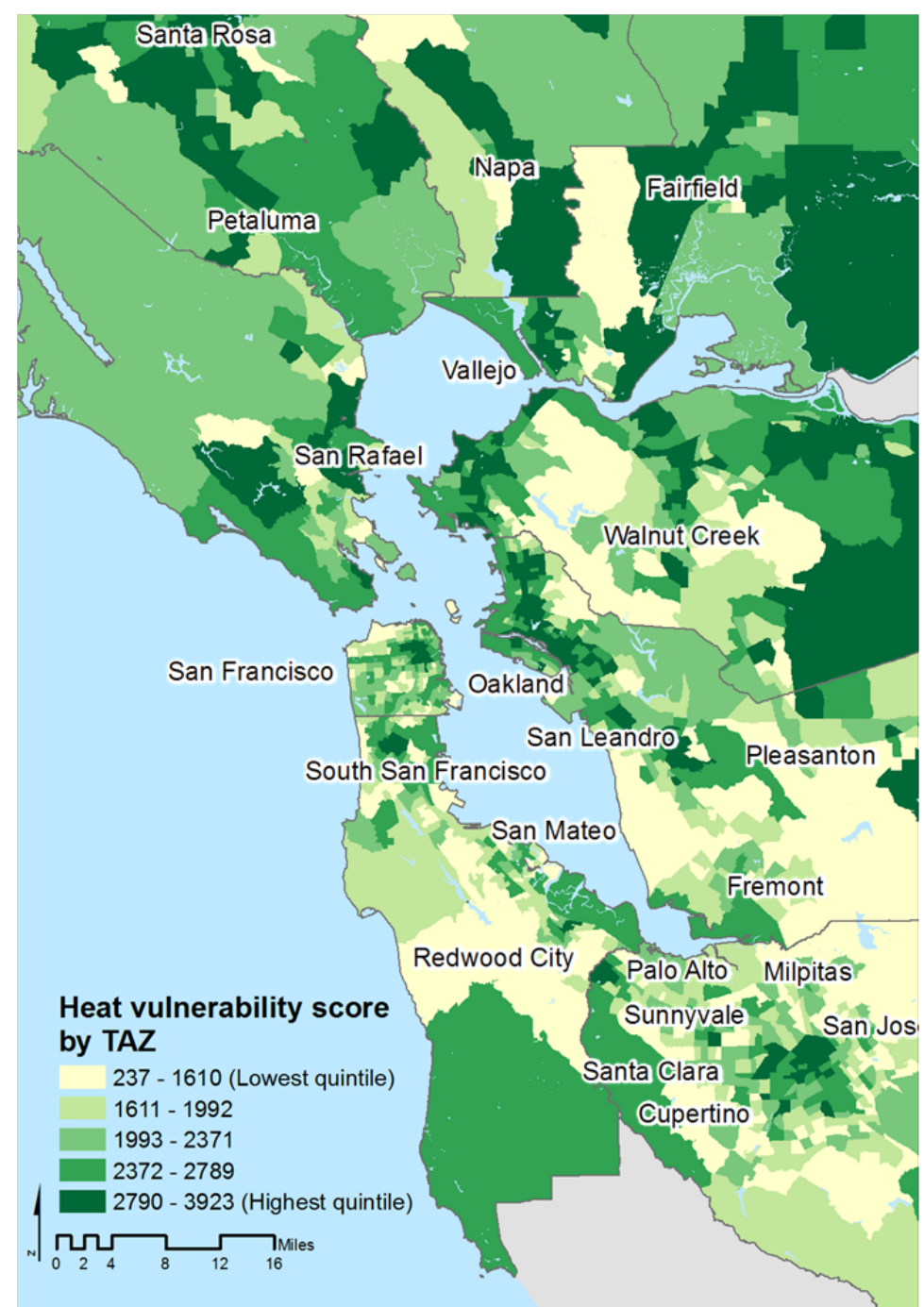

(a)

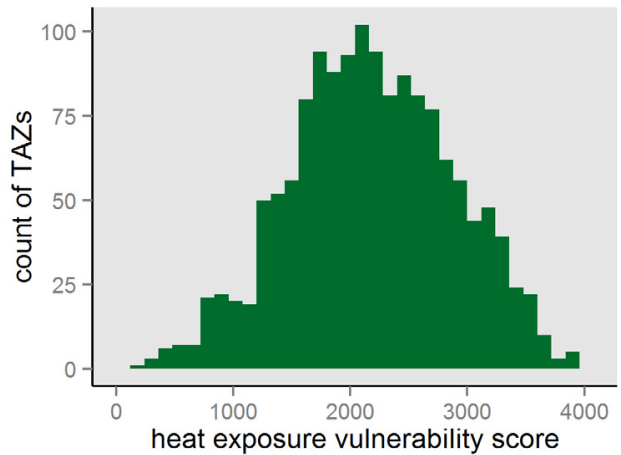

(b)

Fig. 4. Heat exposure vulnerability score for the Bay Area: (a) spatial distribution and (b) histogram of scores.

\section{CONCLUSIONS}

3 Transportation policies and planning efforts in the US are evolving in response to public health 4 goals and the challenges posed by climate change. California has passed the first law in the nation that requires transportation planners to explicitly reduce driving and implicitly increase walking, bicycling, and public transit use. With continued planetary warming and urbanization, air temperatures thought to be extreme in the early part of the 21 st century are likely to become increasingly commonplace as the century progresses. This warming trend will collide with population growth and efforts to develop sustainable transportation systems in California and elsewhere, resulting in potential harm to vulnerable population groups without appropriate planning and mitigation. This work is the first to make the link between travel behavior and extreme heat exposure. Whereas outdoor physical activity is often considered to be an unequivocal societal good, our work shows that it is also associated with potential negative health outcomes during extreme heat situations (Brotherhood 2008). Extreme heat often 15 coincides with periods of high air pollution concentrations (Hanna et al. 2011; Vanos et al. 16 2014), which is one example of how the health of any individual or population is affected by a 
multitude of factors, and outdoor exposure represents only a fraction of an individual's total environmental experience (Klepeis et al. 2001). But we have shown that, because low-income individuals and other vulnerable populations disproportionately use non-motorized transportation, they are more likely to be exposed to extreme heat. We can infer that they will be more likely to suffer the health effects of this exposure as a result. Future work must test transport as a component of the total heat load of individuals as a predictor of health outcomes. Importantly, physical activity imparts some health benefits that would need to be considered in a comprehensive model of health outcomes resulting from travel. The methods developed here can be applied to other locales where similar transportation and urban meteorology data are available.

11 This work suggests a number of transportation policy solutions related to the problem of heat exposure in general and disproportionate exposure in particular. These solutions are consistent with academic and practitioner understandings of the relationship between transportation and land use and can be targeted at places or at people. To the extent that the identified disparities are considered problematic, they can be mitigated by reducing the amount of time that vulnerable population groups spend walking and bicycling. This means either providing cars to vulnerable groups, or improving public transit options. The former is likely to drain already tight household budgets, contribute to worsening air quality, and increase greenhouse gas emissions. On the other hand, making public transit more attractive can benefit an entire region. Public transit trips still require "first and last mile" access, meaning that one has to get to and from the transit vehicle. But these trips are likely to be shorter than a trip that uses biking or walking for its entirety. Areas with high exposure to heat could be targeted for increased scheduled or on-demand service. This service is likely to be most effective in dense urban areas, presenting different challenges for suburban and rural areas that we have identified as important sites of exposure for some residents.

One limitation of the analysis is spatial and temporal resolution $(1 \mathrm{~km}$ grid cells, hourly measurements) of the air temperature data, which we consider to be coarse relative to the scale at which people experience their ambient environment (on the order of meters) as they traverse an urban area with complex micrometeorology (Vanos et al. 2012). The small-scale significant variations of temperatures within a city are especially relevant during summertime heat waves (Harlan et al. 2006; Jenerette et al. 2011). The resolution of and access to such meteorological data is increasing, rapidly following developments in remote sensing satellite capabilities and urban climate models alongside an increase in the number of formal and informal urban meteorological station networks. Increasing resolution is especially important for understanding exposures in urban areas. Urban microscale temperature variations are encompassed within the larger mesoscale phenomenon of the urban heat island (Oke 2003); air and surface temperatures in cities vary from block to block and at even finer spatial scales. Understanding these urban microclimate dynamics at various spatial and temporal scales is critical for understanding how to best provide refuge from heat for city dwellers and those engaged in non-motorized travel. Providing opportunities for hydration, shade, and parks can help to mitigate the potential for heat stress. Other opportunities exist to mitigate urban heat, such as advanced pavement technologies (e.g., permeable pavement), green/white roofs, forced evaporative cooling, and urban agriculture. These are all helpful strategies that could be targeted to specific areas where high concentrations of individuals rely on non-motorized transportation. A second limitation is that this analysis has only incorporated air temperature, whereas human heat stress is ultimately a function of a much 
wider range of biophysical factors including humidity, radiation, wind, and individual health and activity characteristics (Gaitani et al. 2007; Vanos et al. 2010).

The effects of climate change on travel behavior present challenges for the profession of transportation planning as well. Specifically, transportation planners rely upon models of travel demand estimated using historical observations derived from travel-activity surveys. In a warming climate, the longevity of prior relationships can be called into question. As temperatures increase, non-motorized travel will become more difficult to promote as a viable mode. This means that projected future rates of walking, bicycling, and transit use may be overestimates. For a policy like California's SB 375 that relies entirely on modeled estimates of future travel patterns for compliance, this deviation could potentially represent challenges for actually meeting policy goals. Developing a deeper understanding of how travel patterns are likely to change in response to systemic shifts in climate can inform efforts to mitigate exposure and increase non-motorized trip making. Understanding the relationships between urban form, travel behavior, land use, and health outcomes can inform policy and planning today that will lead us to desirable futures tomorrow while ensuring that our travel projections are as accurate as possible.

\section{ACKNOWLEDGEMENTS}

Dr. Karner acknowledges the support of the Walton Sustainability Solutions Initiative at Arizona State University. Dr. Hondula was supported by the Virginia G. Piper Trust Health Policy Informatics Initiative at Arizona State University and the National Science Foundation under grant number BCS-1026865, Central Arizona-Phoenix Long Term Ecological Research Program (CAP LTER). The authors also thank Dave Ory of the Metropolitan Transportation Commission for providing the travel-activity data used in the study. The comments of three anonymous reviewers greatly strengthened the work.

\section{REFERENCES}

Algers, S., J. Eliasson and L.-G. Mattsson (2005). "Is it time to use activity-based urban transport models? A discussion of planning needs and modelling possibilities." The Annals of Regional Science 39(4): 767-789.

Anderson, B. G. and M. L. Bell (2009). "Weather-related mortality: how heat, cold, and heat waves affect mortality in the United States." Epidemiology (Cambridge, Mass.) 20(2): 205.

Barbour, E. and E. A. Deakin (2012). "Smart Growth Planning for Climate Protection." Journal of the American Planning Association 78(1): 70-86.

Barnett, A. G., S. Tong and A. C. A. Clements (2010). "What measure of temperature is the best predictor of mortality?" Environmental Research 110(6): 604-611.

Brotherhood, J. R. (2008). "Heat stress and strain in exercise and sport." Journal of Science and Medicine in Sport 11(1): 6-19.

Chow, W. T. L., W.-C. Chuang and P. Gober (2012). "Vulnerability to Extreme Heat in Metropolitan Phoenix: Spatial, Temporal, and Demographic Dimensions." The Professional Geographer 64(2): 286-302.

Davidson, W., R. Donnelly, P. Vovsha, J. Freedman, S. Ruegg, J. Hicks, J. Castiglione and R. Picado (2007). "Synthesis of first practices and operational research approaches in activity-based travel demand modeling." Transportation Research Part A: Policy and Practice 41(5): 464-488. 
Ebi, K. L. and J. C. Semenza (2008). "Community-Based Adaptation to the Health Impacts of Climate Change." American Journal of Preventive Medicine 35(5): 501-507.

Ewing, R. and R. Cervero (2010). "Travel and the Built Environment." Journal of the American Planning Association 76(3): 265-294.

Gaitani, N., G. Mihalakakou and M. Santamouris (2007). "On the use of bioclimatic architecture principles in order to improve thermal comfort conditions in outdoor spaces." Building and Environment 42(1): 317-324.

Giuliano, G. (2003). "Travel, location and race/ethnicity." Transportation Research Part A: Policy and Practice 37(4): 351-372.

Hajat, S., S. C. Sheridan, M. J. Allen, M. Pascal, K. Laaidi, A. Yagouti, U. Bickis, A. Tobias, D. Bourque, B. G. Armstrong and T. Kosatsky (2010). "Heat-Health Warning Systems: A Comparison of the Predictive Capacity of Different Approaches to Identifying Dangerously Hot Days." American Journal of Public Health 100(6): 1137-1144.

Hanna, A. F., K. B. Yeatts, A. Xiu, Z. Zhu, R. L. Smith, N. N. Davis, K. D. Talgo, G. Arora, P. J. Robinson and Q. Meng (2011). "Associations between ozone and morbidity using the Spatial Synoptic Classification system." Environmental Health 10(49): 15.

Hanson, S. and M. Schwab (1987). "Accessibility and intraurban travel." Environment and Planning A 19(6): 735-748.

Harlan, S. L., A. J. Brazel, L. Prashad, W. L. Stefanov and L. Larsen (2006). "Neighborhood microclimates and vulnerability to heat stress." Social Science \& Medicine 63(11): 28472863.

Harlan, S. L., J. H. Declet-Barreto, W. L. Stefanov and D. B. Petitti (2012). "Neighborhood effects on heat deaths: social and environmental predictors of vulnerability in Maricopa County, Arizona." Environmental Health Perspectives 121(2): 197-204.

Hondula, D. M. and A. G. Barnett (2014). "Heat-related morbidity in Brisbane, Australia: spatial variation and area-level predictors." Environmental health perspectives.

Hondula, D. M., R. E. Davis, M. J. Leisten, M. V. Saha, L. M. Veazey and C. R. Wegner (2012). "Fine-scale spatial variability of heat-related mortality in Philadelphia County, USA, from 1983-2008: a case-series analysis." Environ Health 11(16): 1-11.

Hondula, D. M., M. Georgescu and R. C. Balling Jr (2014). "Challenges associated with projecting urbanization-induced heat-related mortality." Science of The Total Environment 490: 538-544.

Hosking, J., P. Mudu and C. Dora (2011). Health in the Green Economy: Health Co-Benefits of Climate Change Mitigation - Transport Sector. Geneva, Switzerland, World Health Organization

Karner, A. and D. Niemeier (2013). "Civil rights guidance and equity analysis methods for regional transportation plans: a critical review of literature and practice." Journal of Transport Geography 33: 126-134.

Kitamura, R. (1988). "An evaluation of activity-based travel analysis." Transportation 15: 9-34.

Klepeis, N. E., W. C. Nelson, W. R. Ott, J. P. Robinson, A. M. Tsang, P. Switzer, J. V. Behar, S. C. Hern and W. H. Engelmann (2001). "The National Human Activity Pattern Survey (NHAPS): a resource for assessing exposure to environmental pollutants." Journal of exposure analysis and environmental epidemiology 11(3): 231-252.

Kovach, M. M., C. E. Konrad and C. M. Fuhrmann (2015). "Area-level risk factors for heatrelated illness in rural and urban locations across North Carolina, USA." Applied Geography 60: 175-183. 
Kuras, E. R., D. M. Hondula and J. Brown-Saracino (2015). "Heterogeneity in Individually Experienced Temperatures (IETs) within an Urban Neighborhood: Insights from a New Approach to Measuring Heat Exposure." International Journal of Biometeorology.

Maizlish, N., J. Woodcock, S. Co, B. Ostro, A. Fanai and D. Fairley (2012). Health Co-Benefits and Transportation-Related Reductions in Greenhouse Gas Emissions in the Bay Area: Technical Report, California Department of Public Health.

Marmot, M., S. Friel, R. Bell, T. A. J. Houweling and S. Taylor (2008). "Closing the gap in a generation: health equity through action on the social determinants of health." The Lancet 372(9650): 1661-1669.

McMichael, A. J., P. Wilkinson, R. S. Kovats, S. Pattenden, S. Hajat, B. Armstrong, N. Vajanapoom, E. M. Niciu, H. Mahomed, C. Kingkeow, M. Kosnik, M. S. O’Neill, I. Romieu, M. Ramirez-Aguilar, M. L. Barreto, N. Gouveia and B. Nikiforov (2008). "International study of temperature, heat and urban mortality: the 'ISOTHURM' project." International Journal of Epidemiology 37(5): 1121-1131.

McNally, M. G. and C. Rindt (2007). The Activity-Based Approach. In Handbook of Transport Modeling, 2nd Edition. D. A. Hensher and K. J. Button. New York, Pergamon.

Miller, N. L., K. Hayhoe, J. Jin and M. Auffhammer (2008). "Climate, extreme heat, and electricity demand in California." Journal of Applied Meteorology and Climatology 47(6): 1834-1844.

MTC and ABAG (2013). Plan Bay Area: Strategy for a Sustainable Region. Oakland, CA, Metropolitan Transportation Commission and Association of Bay Area Governments.

Oke, T. (2003). Boundary Layer Climates, Second Edition. London, Routledge/Taylor and Francis.

Ortúzar, J. D. and L. G. Willumsen (2011). Modelling Transport, 4th Edition. Chichester, UK, John Wiley \& Sons.

Patz, J. A., D. Campbell-Lendrum, T. Holloway and J. A. Foley (2005). "Impact of regional climate change on human health." Nature 438(7066): 310-317.

Plaut, P. O. (2005). "Non-motorized commuting in the US." Transportation Research Part D: Transport and Environment 10(5): 347-356.

Polsky, C., R. Neff and B. Yarnal (2007). "Building comparable global change vulnerability assessments: The vulnerability scoping diagram." Global Environmental Change 17(3-4): 472-485.

Pucher, J., R. Buehler, D. Merom and A. Bauman (2011). "Walking and Cycling in the United States, 2001-2009: Evidence From the National Household Travel Surveys." American Journal of Public Health 101(S1): S310-S317.

Pucher, J. and J. L. Renne (2003). "Socioeconomics of Urban Travel: Evidence from the 2001 NHTS." Transportation Quarterly 57(3): 49-77.

Quinn, A., J. D. Tamerius, M. Perzanowski, J. S. Jacobson, I. Goldstein, L. Acosta and J. Shaman (2014). "Predicting indoor heat exposure risk during extreme heat events." Science of the Total Environment 490: 686-693.

Reid, C. E., M. S. O'Neill, C. J. Gronlund, S. J. Brines, A. V. Diez-Roux, D. G. Brown and J. D. Schwartz (2009). "Mapping community determinants of heat vulnerabiliy." Environmental Health Perspectives 117(11): 1730-1736.

Revi, A., D. E. Satterthwaite, F. Aragón-Durand, J. Corfee-Morlot, R. B. R. Kiunsi, M. Pelling, D. C. Roberts and W. Solecki (2014). Urban areas. In Climate Change 2014: Impacts, Adaptation, and Vulnerability. Part A: Global and Sectoral Aspects. Contribution of 
Working Group II to the Fifth Assessment Report of the Intergovernmental Panel of Climate Change. C. B. Field, V. R. Barros, D. J. Dokkenet al. Cambridge, United Kingdom and New York, NY, USA, Cambridge University Press.

Rey, G., A. Fouillet, P. Bessemoulin, P. Frayssinet, A. Dufour, E. Jougla and D. Hémon (2009). "Heat exposure and socio-economic vulnerability as synergistic factors in heat-waverelated mortality." European journal of epidemiology 24(9): 495-502.

Saelens, B. E., J. F. Sallis and L. D. Frank (2003). "Environmental correlates of walking and cycling: findings from the transportation, urban design, and planning literatures." Annals of behavioral medicine 25(2): 80-91.

Sallis, J. F., L. D. Frank, B. E. Saelens and M. K. Kraft (2004). "Active transportation and physical activity: opportunities for collaboration on transportation and public health research." Transportation Research Part A: Policy and Practice 38(4): 249-268.

San Francisco Department of Public Health (2013). Extreme Heat Response Plan: An Annex to the SFDPH Emergency Operations Plan. San Francisco, CA, Program on Health, Equity and Sustainability.

Stone, B., Jr., J. Vargo, P. Liu, D. Habeeb, A. DeLucia, M. Trail, Y. Hu and A. Russell (2014). "Avoided Heat-Related Mortality through Climate Adaptation Strategies in Three US Cities." PLoS ONE 9(6): e100852.

Taylor, B. D. and E. A. Morris (2015). "Public transportation objectives and rider demographics: are transit's priorities poor public policy?" Transportation 42(2): 347-367.

Thornton, P. E., S. W. Running and M. A. White (1997). "Generating surfaces of daily meteorological variables over large regions of complex terrain." Journal of Hydrology 190(3-4): 214-251.

Turner, B. L., R. E. Kasperson, P. A. Matson, J. J. McCarthy, R. W. Corell, L. Christensen, N. Eckley, J. X. Kasperson, A. Luers, M. L. Martello, C. Polsky, A. Pulsipher and A. Schiller (2003). "A framework for vulnerability analysis in sustainability science." Proceedings of the National Academy of Sciences 100(14): 8074-8079.

Uejio, C. K., J. D. Tamerius, J. Vredenburg, G. Asaeda, D. A. Isaacs, J. Braun, A. Quinn and J. P. Freese (In press). "Summer indoor heat exposure and respiratory and cardiovascular distress calls in New York City, NY, U.S." Indoor Air.

Uejio, C. K., O. V. Wilhelmi, J. S. Golden, D. M. Mills, S. P. Gulino and J. P. Samenow (2011). "Intra-urban societal vulnerability to extreme heat: The role of heat exposure and the built environment, socioeconomics, and neighborhood stability." Health \& Place 17(2): 498507.

US Census Bureau (2014). The 2008-2012 ACS 5-Year Summary File Technical Documentation. Washington, DC, US Department of Commerce, Economics and Statistics Administration.

Vanos, J. K., S. Cakmak, L. S. Kalkstein and A. Yagouti (2014). "Association of weather and air pollution interactions on daily mortality in 12 Canadian cities." Air Quality, Atmosphere \& Health: 1-14.

Vanos, J. K., J. S. Warland, T. J. Gillespie and N. A. Kenny (2010). "Review of the physiology of human thermal comfort while exercising in urban landscapes and implications for bioclimatic design." International Journal of Biometeorology 54(4): 319-334.

Vanos, J. K., J. S. Warland, T. J. Gillespie, G. A. Slater, R. D. Brown and N. A. Kenny (2012). "Human Energy Budget Modeling in Urban Parks in Toronto and Applications to 
Emergency Heat Stress Preparedness." Journal of Applied Meteorology and Climatology 51(9): 1639-1653.

Wolf, T. and G. McGregor (2013). "The development of a heat wave vulnerability index for

$4 \quad$ London, United Kingdom." Weather and Climate Extremes 1: 59-68.

5 Zhang, K., R. B. Rood, G. Michailidis, E. M. Oswald, J. D. Schwartz, A. Zanobetti, K. L. Ebi and M. S. O'Neill (2012). "Comparing exposure metrics for classifying 'dangerous heat'in heat wave and health warning systems." Environment International 46(1): 23-29. 